\title{
On the use of radar reflectivity for estimation of the areal reduction factor
}

\author{
F. Lombardo, F. Napolitano, and F. Russo \\ Department of Hydraulics, Highways and Roads, University of Rome "La Sapienza", 00184 Rome, Italy
}

Received: 11 October 2005 - Revised: 1 March 2006 - Accepted: 1 March 2006 - Published: 17 May 2006

\begin{abstract}
In order to estimate the rainfall fields over an entire basin raingauge, pointwise measurements need to be interpolated and the small-scale variability of rainfall fields can lead to biases in the rain rate estimation over an entire basin, above all for small or medium size mountainous and urban catchments.

For these reasons, several raingauges should be installed in different places in order to determine the spatial rainfall distribution during the evolution of the natural phenomena over the selected area.

In technical applications, many empirical relations are used in order to deduce heavy areal rainfall, when just one raingauge is available.

In this work, we studied the areal reduction factor (ARF) using radar reflectivity maps collected with the Polar 55C, a C-band Doppler dual polarized coherent weather radar with polarization agility and with a $0.9^{\circ}$ beamwidth.

The radar rainfall estimates, for an area of $1 \mathrm{~km}^{2}$, were integrated for heavy rainfall with an upscaling process, until we had rainfall estimate for an area of $900 \mathrm{~km}^{2}$.

The results obtained for a significant amount of data by using this technique are compared with the most important relations of the areal reduction factor reported in the literature.
\end{abstract}

\section{Introduction}

Many observational studies of rainfall identify some specific elements of rainfall fields in space by underlining the trend of rain cells to cluster inside larger-scale structures called "small mesoscale areas" (SMSA), contained inside large mesoscale areas (LMSA), which, in turn, are contained inside synoptic areas (Austin and Houze, 1972). These re-

Correspondence to: F. Lombardo

(federico.lombardo@uniroma1.it) gions are all characterised by different rainfall intensities where rain cells have the highest intensities.

Because of this particular precipitation structure we can observe both high intensity rainfall clustering in small areas and rainfall intensity decreasing with distance from the point of highest rain intensity.

The reduction of high intensity rainfalls with increasing areas is a key issue in many hydrological problems, e.g. in designing hydraulic structures for flood control as in urban drainage systems (Bacchi and Ranzi, 1996).

The areal reduction factor (ARF) was introduced to solve this problem. The National Environmental Research Council (NERC) Flood Studies Report (NERC, 1975) defined the ARF to be the factor which has to be applied to point rainfall measurements of specified durations and return periods in order to obtain areal rainfall for the same durations and return periods. Thus the ARF usually ranges from 0 to 1 .

Earlier, the National Weather Service (NWS, 1958) developed a set of curves, originally based on major storms recorded at points in seven dense raingauge networks in the United States of America, with records from 7 to 15 years. The storm durations ranged from $30 \mathrm{~min}$ to $24 \mathrm{~h}$, and the plots showed the areal reduction for areas from 250 to $1000 \mathrm{~km}^{2}$; subsequently, observations from 13 other networks were found to correspond, on average, with the original curves. These results are widely adopted (see, e.g., World Meteorological Organization (WMO), 1986). Nevertheless, many empirical formulae have been derived to express the areal variability of storm rainfall, but they are strongly dependent on the specific geographic and climate conditions to which they have been applied originally.

Roche (1966), instead, developed a theoretical approach to point and areal rainfall based on the correlation structure of intense storms. Rodriguez-Iturbe and Mejia (1974) extended the theory, introducing variance function and variance reduction factors. On the other hand, Bacchi and Ranzi (1996) presented a stochastic derivation of the ARF based on crossing

Published by Copernicus GmbH on behalf of the European Geosciences Union. 


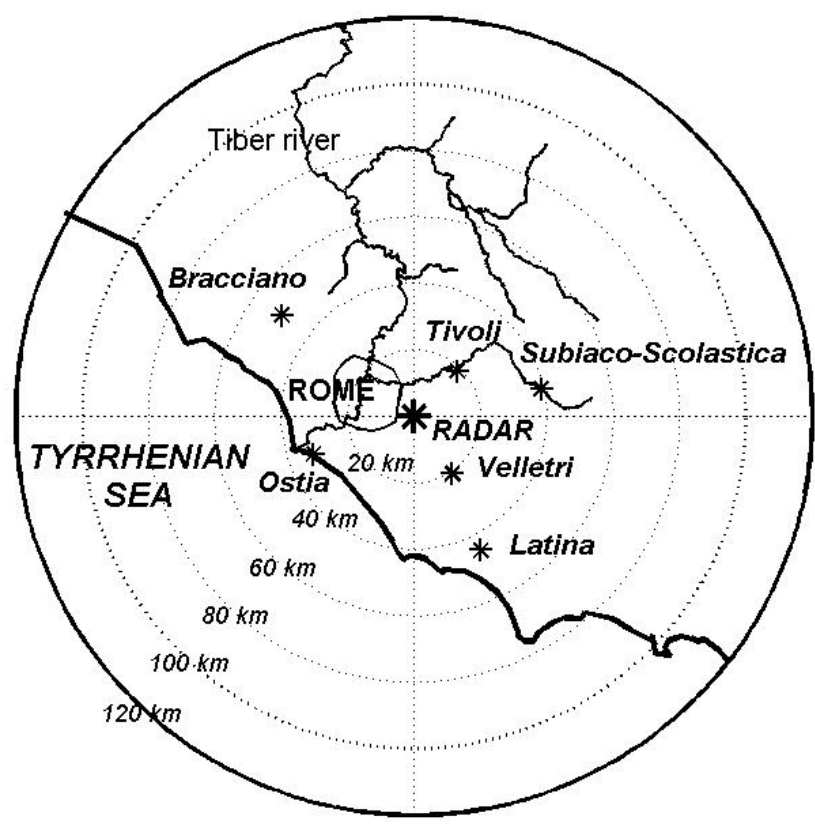

Fig. 1. Case-study region in relation to the radar location (in the centre), the Rome's ring road, the coast-line, the hydrographical network of the river Tiber, and the location of selected raingauges.

properties of random fields. Later, Sivapalan and Blösch (1998) analysed the derivation of the ARF for extreme storm rainfall and also used a variance reduction factor.

Subsequently, Asquith and Famiglietti (2000), assuming a probability equivalence between point and areal rainfall as in the characteristic correlation length procedure of Roche (1966) and others, considered the distribution of catchment's rainfall surrounding an annual-precipitation maxima. Shortly afterward, De Michele et al. (2001) adopted a statistical approach to the ARF of extreme storm rainfall based on its scaling properties in space and time.

More recently, Veneziano and Langousis (2005) analysed scaling properties of the ARF under the condition that spacetime rainfall has multifractal scale invariance.

In this work, we studied the areal reduction factor using radar reflectivity maps collected with the Polar 55C weather radar. The work is organized as follows.

In Sect. 2, we describe characteristics of the Polar 55C weather radar and procedures used to convert observed reflectivity into rainfall intensities.

In Sect. 3, rainfall time series recorded by 6 raingauges are analysed in order to find the values of heavy rainfall intensities in the study area.

In Sect. 4, we explain the assumed methodology for the upscaling process.

Finally, in Sect. 5, results are shown and discussed.

\section{The Polar 55C weather radar}

The Polar 55C is a C-band $(5.5 \mathrm{GHz}, \lambda=5.4 \mathrm{~cm})$ Doppler dual polarized coherent weather radar with polarization agility and with a $0.9^{\circ}$ beamwidth, managed by the Institute of Atmospheric Sciences and Climate of the National Research Council, Italy.

The radar is located $15 \mathrm{~km}$ South-East of Rome, in the Tor Vergata research area (lat. $41^{\circ} 50^{\prime} 24^{\prime \prime} \mathrm{N}$, lon. $12^{\circ} 38^{\prime} 50^{\prime \prime} \mathrm{E}$, $102 \mathrm{~m}$ above sea level). Figure 1 shows the case-study region in relation to the radar location (in the centre), the city ring road, the coast-line and the hydrographical network of the river Tiber.

In this scheme, the radar can measure the most used horizontally reflectivity factor $\left(Z_{h}\right)$, the differential reflectivity $\left(Z_{d r}\right)$ and the differential phase shift $\left(\Phi_{d p}\right)$. Radar measurements are obtained by averaging 64 pulses with a range-bin resolution of $75 \mathrm{~m}$, up to $120 \mathrm{~km}$ away from the radar location. A radar image is available every five minutes.

Preliminary analyses on plan position indicators (PPI) collected at different elevations were performed in order to find the best antenna elevation for radar rainfall estimation. Furthermore, reflectivity maps were adequately corrected by filtering out all of the ground-clutters by using a specific algorithm based upon the backscattering signal variance of the differential reflectivity (Gorgucci et al., 1995; Russo et al., 2005).

In order to convert observed reflectivity into rainfall intensity, an algorithm based on a Z-R relation is used. This relation was obtained for $\mathrm{C}$-band by means of a non-linear regression analysis (Russo et al., 2005):

$R=7.27 \cdot 10^{-2} Z_{h}^{0.62}$

\section{Preliminary analysis}

The objective of this preliminary analysis is to calculate values of heavy rainfall over the whole study area as a function of duration and return period.

Therefore, the intensity-duration (ID) curves of the annual maxima for the 6 recording raingauges indicated in the Fig. 1 were constructed to this end (refer to Koutsoyiannis et al., 1998, for details). All raingauges had at least 30 years of annual maximum series and were placed in such a way as to cover adequately the radar scanning region.

The data used in this preliminary analysis were taken from the Hydrological Annals - published by the "Regione Lazio - Ufficio Idrografico e Mareografico" - for each raingauge and they are the annual maximum series of rainfall depth for the following durations: $\delta=1,3,6,12,24 \mathrm{~h}$.

The expansion to time ranges shorter than $1 \mathrm{~h}$ - very interesting for urban hydrology - is possible by using published information. 

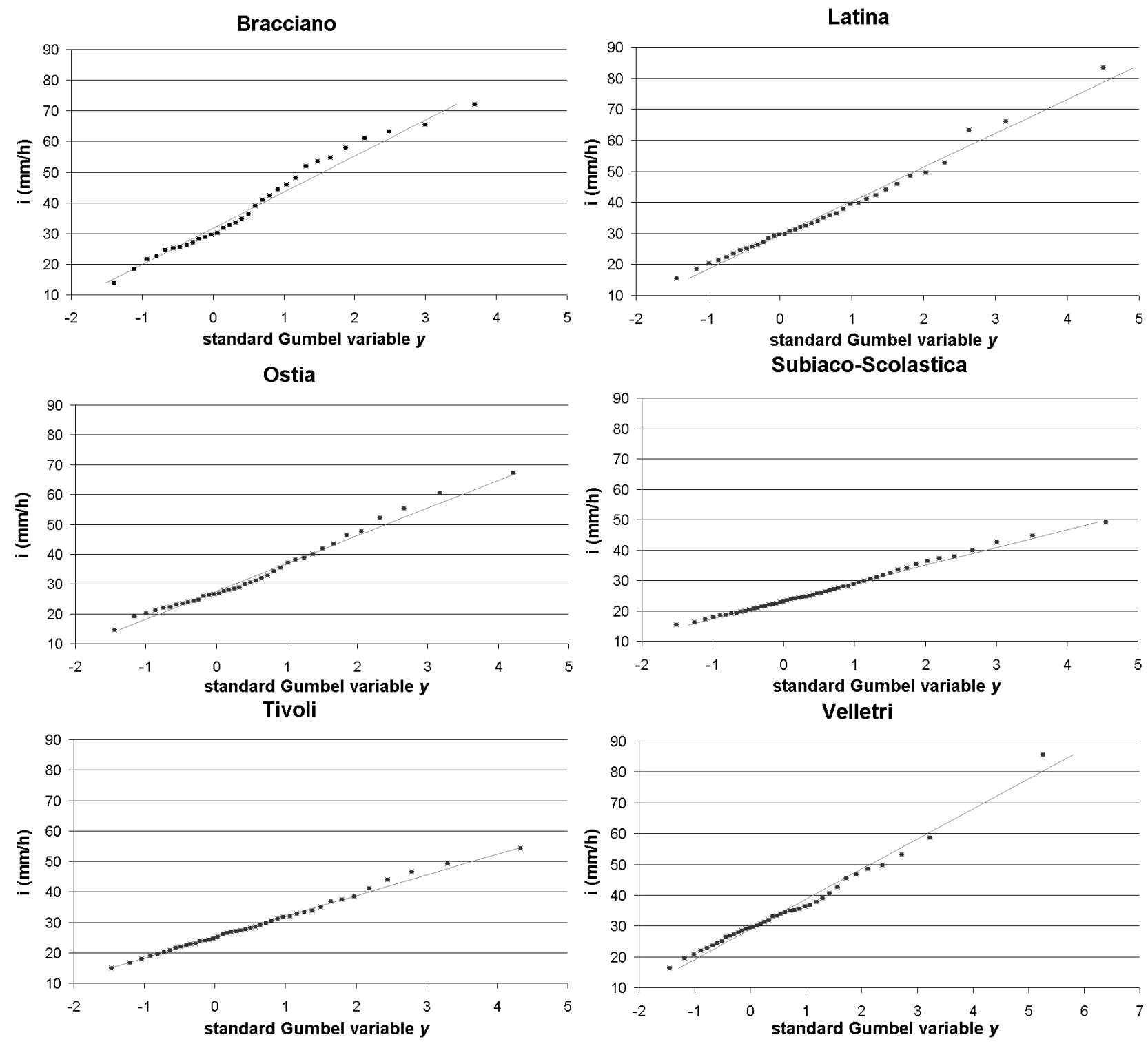

Fig. 2. Annual maximum rainfall intensities for the 6 raingauges plotted using Gringorten's formula on a probability scale for the Extreme Value Type I distribution.

In fact, the ratio $r_{\delta}$ between the rainfall depth of very short $\delta$ duration and that of 1-hour duration depends very little on the location:

$r_{\delta}=\frac{h_{\delta}}{h_{1 h}}$

The same can be said about rain intensity:

$\rho_{\delta}=\frac{h_{\delta}}{h_{1 h}} \cdot \frac{1}{\delta}$

Making the ID relationships pass through short-duration intensities derived from the literature $\rho_{\delta}$ ratios, the expansion to time ranges shorter than one hour is obtained for the said curves.
In the case studied, the ID relationships pass through the 5-min rainfall intensity obtained from the $\rho_{5^{\prime}}=3.336$ ratio related to the Roma Macao raingauge station (Calenda et al., 1993).

Subsequently frequency analysis is applied to the annual data.

To a first approximation, data are supposed to be distributed according to the Extreme Value Type I (EV1) distribution. However, there is ongoing discussion about the inappropriateness of the EV1 distribution in estimating hydrological extremes (Koutsoyiannis, 2004a, b), but this is not key in our work because the values obtained by this preliminary analysis are just used as thresholds, as described in the next section. 


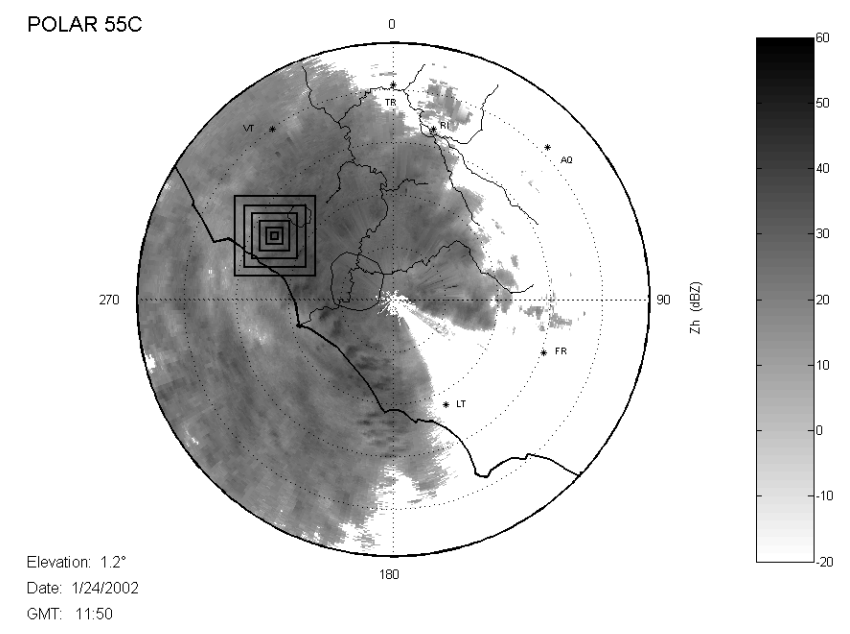

Fig. 3. Size increasing process of a pixel.

In order to calculate the non-exceedence probability value $F_{k}$ assigned to each ranked value of observed data, the Gringorten (1963) formula is used (Chow et al., 1988):

$F_{k}=1-\frac{k-0.44}{N+1-0.88}$

Thus the intensity-duration relations (ID) become intensityduration-frequency relations (IDF), which are characterised, for each $k$, by a constant frequency.

IDF relations can be interpreted in probabilistic terms by assuming that cumulative probability is constant in each curve $\mathrm{i}_{\delta}(\delta): P\left[i_{\delta}(\delta)\right]=\operatorname{const}(\delta)$.

This means that the rain intensity $i_{\delta}$ is an invariant-scale phenomenon under $\delta$ duration.

Thus, the parameters of the rain probability function were estimated for each recording raingauge by fitting an EV1 distribution to the observed data. In order to graphically check the goodness of fit, the observed data are plotted, each raingauge separately, against the fitted curve on Gumbel probability paper (see Fig. 2). All plots show that each fitted line is consistent with the relevant observed data.

Subsequently, the rain intensity estimates were calculated for each duration and return period selected and the results are shown in Table 1 where $\delta$ is the duration expressed in minutes, $T$ is the return period and $i$ is the rainfall rate expressed in $\mathrm{mm} / \mathrm{h}$.

Finally, the rain intensities over the entire radar field of view were calculated for the prefixed 4 return periods and 5 durations. To a first approximation the arithmetic mean of the rain intensities was calculated for each duration and return period in order to evaluate one intensity value over the whole radar scanning region. In fact the areal average rainfall rates determined by using the Thiessen method are quite the same.

The results are shown in Table 2.
Table 1. Rain intensity values $(\mathrm{mm} / \mathrm{h})$ estimated for each recording raingauge, duration $(\delta=1,5,10,60$ and $120 \mathrm{~min})$, and return period ( $T=2,10,25$ and 50 years) selected.

\begin{tabular}{|c|c|c|c|c|c|}
\hline & \multicolumn{5}{|c|}{$T=2$ years } \\
\hline & $\mathrm{i}_{\delta=1}$ & $\mathrm{i}_{\delta=5}$ & $\mathrm{i}_{\delta=10}$ & $\mathrm{i}_{\delta=60}$ & $\mathrm{i}_{\delta=120}$ \\
\hline Subiaco Scolastica & 114.0 & 84.8 & 66.1 & 25.4 & 16.4 \\
\hline Tivoli & 116.8 & 91.9 & 73.6 & 27.6 & 16.9 \\
\hline Latina & 140.8 & 111.4 & 89.4 & 33.4 & 20.4 \\
\hline Velletri & 140.9 & 108.5 & 85.9 & 32.5 & 20.4 \\
\hline Ostia & 131.5 & 103.2 & 82.4 & 30.9 & 19.1 \\
\hline \multirow[t]{3}{*}{ Bracciano } & 154.0 & 120.0 & 95.5 & 36.0 & 22.3 \\
\hline & \multicolumn{5}{|c|}{$T=10$ years } \\
\hline & $\mathrm{i}_{\delta=1}$ & $\mathrm{i}_{\delta=5}$ & $\mathrm{i}_{\delta=10}$ & $\mathrm{i}_{\delta=60}$ & $\mathrm{i}_{\delta=120}$ \\
\hline Subiaco Scolastica & 163.5 & 121.5 & 94.8 & 36.4 & 23.5 \\
\hline Tivoli & 171.3 & 134.9 & 107.9 & 40.4 & 24.8 \\
\hline Latina & 227.6 & 180.2 & 144.6 & 54.0 & 33.0 \\
\hline Velletri & 220.7 & 169.9 & 134.5 & 50.9 & 32.0 \\
\hline Ostia & 206.2 & 161.9 & 129.3 & 48.5 & 29.9 \\
\hline \multirow[t]{3}{*}{ Bracciano } & 249.1 & 194.0 & 154.4 & 58.1 & 36.1 \\
\hline & \multicolumn{5}{|c|}{$T=25$ years } \\
\hline & $\mathrm{i}_{\delta=1}$ & $\mathrm{i}_{\delta=5}$ & $\mathrm{i}_{\delta=10}$ & $\mathrm{i}_{\delta=60}$ & $\mathrm{i}_{\delta=120}$ \\
\hline Subiaco Scolastica & 188.4 & 140.1 & 109.2 & 42.0 & 27.1 \\
\hline Tivoli & 198.7 & 156.5 & 125.2 & 46.9 & 28.8 \\
\hline Latina & 271.4 & 214.8 & 172.4 & 64.4 & 39.3 \\
\hline Velletri & 260.8 & 200.8 & 158.9 & 60.2 & 37.8 \\
\hline Ostia & 243.8 & 191.4 & 152.8 & 57.4 & 35.3 \\
\hline \multirow[t]{3}{*}{ Bracciano } & 296.9 & 231.3 & 184.0 & 69.3 & 43.0 \\
\hline & \multicolumn{5}{|c|}{$T=50$ years } \\
\hline & $\mathrm{i}_{\delta=1}$ & $\mathrm{i}_{\delta=5}$ & $\mathrm{i}_{\delta=10}$ & $\mathrm{i}_{\delta=60}$ & $\mathrm{i}_{\delta=120}$ \\
\hline Subiaco Scolastica & 206.8 & 153.8 & 119.9 & 46.1 & 29.7 \\
\hline Tivoli & 219.1 & 172.5 & 138.0 & 51.7 & 31.7 \\
\hline Latina & 303.8 & 240.5 & 193.0 & 72.1 & 44.0 \\
\hline Velletri & 290.6 & 223.8 & 177.1 & 67.1 & 42.1 \\
\hline Ostia & 271.7 & 213.3 & 170.3 & 63.9 & 39.4 \\
\hline Bracciano & 332.4 & 258.9 & 206.0 & 77.6 & 48.2 \\
\hline
\end{tabular}

\section{Methodology}

The aim of our work is to analyse the ARF trend with increasing area at different durations and return periods. Mathematically, the ARF formula used in our work is dimensionless and can be expressed as follows:

$\operatorname{ARF}(\delta, T)=\frac{i_{A}(\delta, T)}{i_{A=1}(\delta, T)}$

where $\delta$ is the duration, $T$ is the return period, the numerator and denominator of the right term represent the rainfall rate over an area not less than $1 \mathrm{~km}^{2}$ and the rainfall rate over an area equal to $1 \mathrm{~km}^{2}$ respectively. This ARF definition (Eq. 5) is quite different from the standard definition of the ARF (see NERC, 1975). According to the standard definition, the ARF 

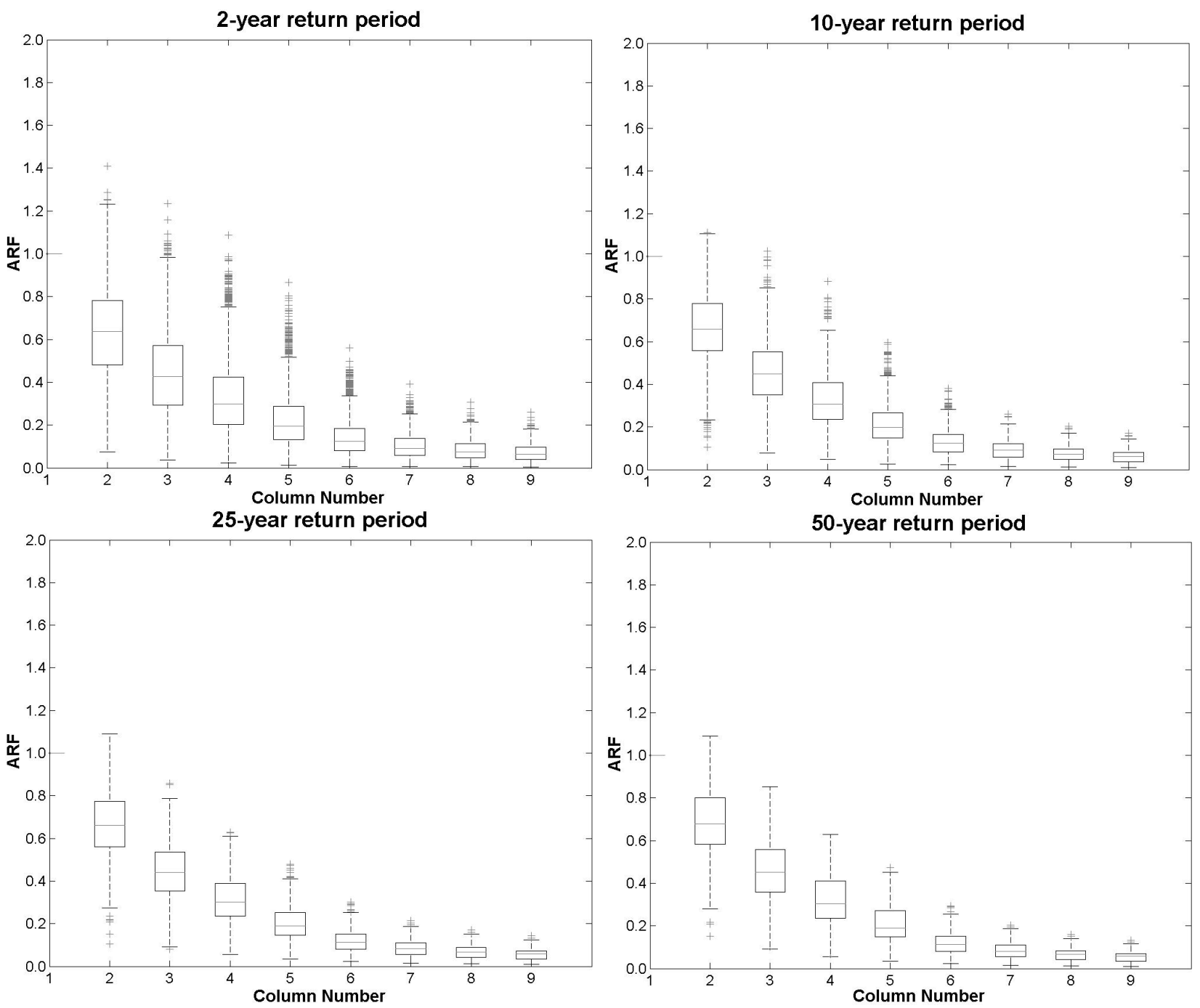

Fig. 4. Box plots of the data sample for each return period selected and the 1-min duration. Each column number represents the ARF values over a selected area $(1=1 \mathrm{~km} \times 1 \mathrm{~km}, 2=3 \mathrm{~km} \times 3 \mathrm{~km}, 3=5 \mathrm{~km} \times 5 \mathrm{~km}, 4=7 \mathrm{~km} \times 7 \mathrm{~km}, 5=10 \mathrm{~km} \times 10 \mathrm{~km}, 6=15 \mathrm{~km} \times 15 \mathrm{~km}, 7=20 \mathrm{~km} \times 20 \mathrm{~km}$, $8=25 \mathrm{~km} \times 25 \mathrm{~km}, 9=30 \mathrm{~km} \times 30 \mathrm{~km}$ pixel $)$.

is the ratio between an areal rainfall - obtained by interpolation of point rainfall measurements given by a raingauge network - and a point rainfall measured by only one raingauge. The high fluctuation of raingauge measurements above all for short durations - and the big errors introduced by the interpolation of point rainfall measurements to obtain areal rainfall made us think of calculating the ARF using an upscaling process in which no point rainfall measurements are considered. Thus, no interpolation is applied to our data set. The scaling law is obtained by the ratio between the radar rainrate estimates over an area ranging from $1 \mathrm{~km}^{2}$ to $900 \mathrm{~km}^{2}$ and the radar rainrate estimates over a $1 \mathrm{~km}^{2}$ area.

On the basis of these considerations, the radar scanning field was discretized using a grid with $1 \mathrm{~km} \times 1 \mathrm{~km}$ pixel. The rainfall intensity over each pixel - for each PPI recordered by the radar - is calculated as follows:
1. evaluate the total range-bin number which falls within the pixel considered;

2. evaluate the range-bin number with a valid value - i.e., a value which is recognized to be a real rainfall datum by the ground-clutter removal algorithm (Russo et al., 2005) - which falls within the pixel considered;

3. in order to make the rainfall measurement meaningful for a pixel, we have assumed a threshold so that the number of valid range-bins must be at least equal to $25 \%$ of the total number of range-bins which fall within the same pixel;

4. if the above condition proves valid, the rainfall intensity over the pixel is calculated by averaging the rainfall 

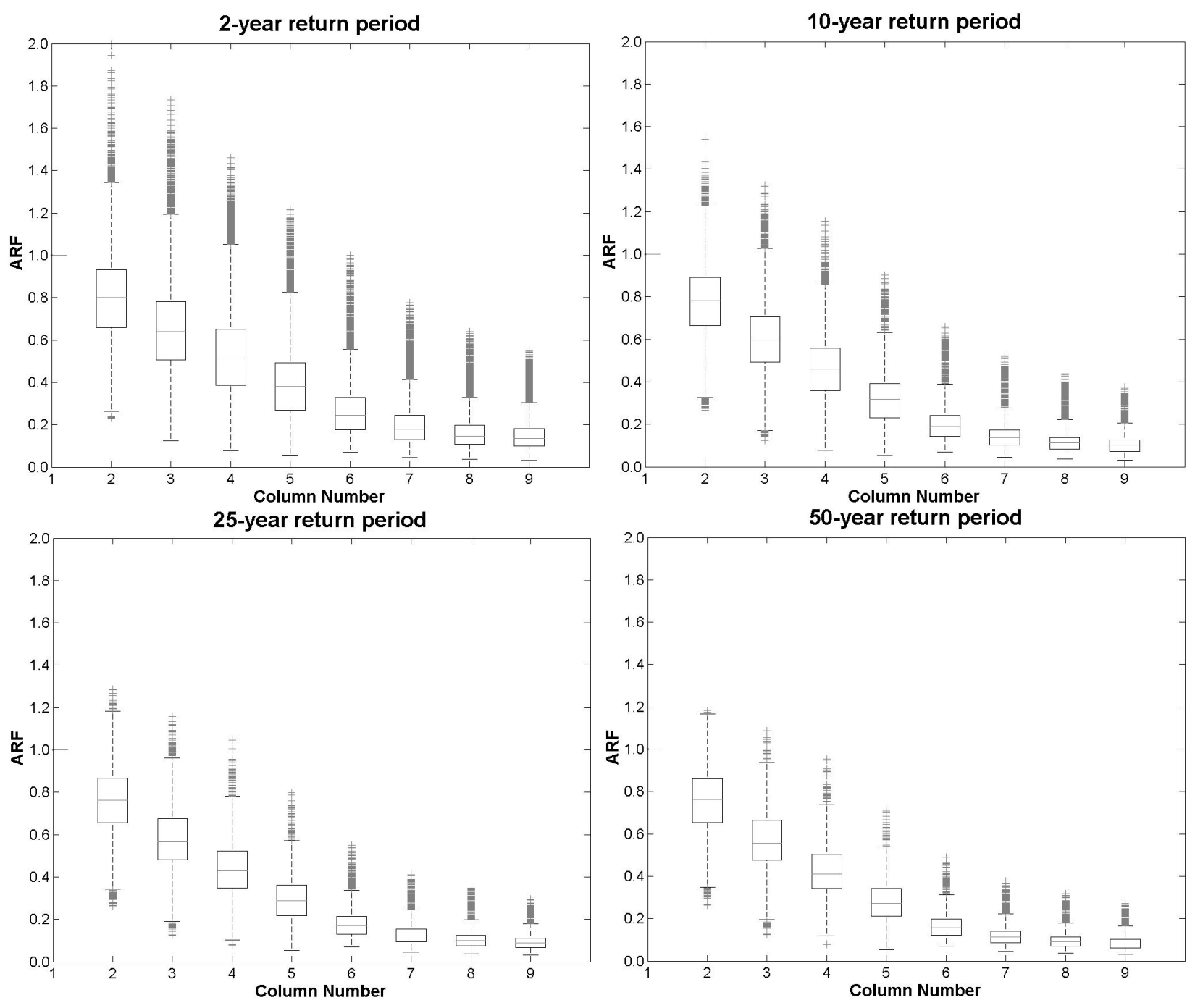

Fig. 5. Box plots of the data sample for each return period selected and the 120-min duration.

intensity values of all valid range-bins. Otherwise, the no-data value is given to the pixel.

In order to estimate the rainfall intensity for selected durations $(\delta=1,5,10,60,120 \mathrm{~min})$, we assumed that the rainfall intensity of a single radar image lasts one minute. Therefore, this is the minimum time resolution used. This hypothesis is based upon the fact that the time necessary for the antenna to record an entire PPI - which would give the information about the whole observation area - lasts about one minute $(\sim 55 \mathrm{~s})$. Thus, the utmost temporal resolution available is equal to 1 PPI per minute and this is due to technical shortcomings.

For higher temporal aggregations, a vector with time intervals between the consecutive PPIs is built. If the time intervals required are longer than $7 \mathrm{~min}$, the no-data value is given to the corresponding element of the vector with the aim of identifying possible malfunctioning and interruptions in radar recording.

A "time mobile window" - which is as large as the temporal aggregation to be studied - scans in time the entire rain event for each pixel of the grid. For example, the time mobile window considers three consecutive PPIs when the temporal aggregation lasts $10 \mathrm{~min}$.

If the pixel rainfall intensity values considered in this window are all valid and hold valid time intervals, the rainfall intensity value is determined as the arithmetic mean value in the same window.

At this point, we compare the rain intensity thresholds calculated by the preliminary analysis with the rain rate estimated by the radar over a $1 \mathrm{~km} \times 1 \mathrm{~km}$ region, because we assume they are quite similar. Therefore, we compare the values calculated for each considered duration with the relevant rainfall intensities determined by the arithmetic-mean 

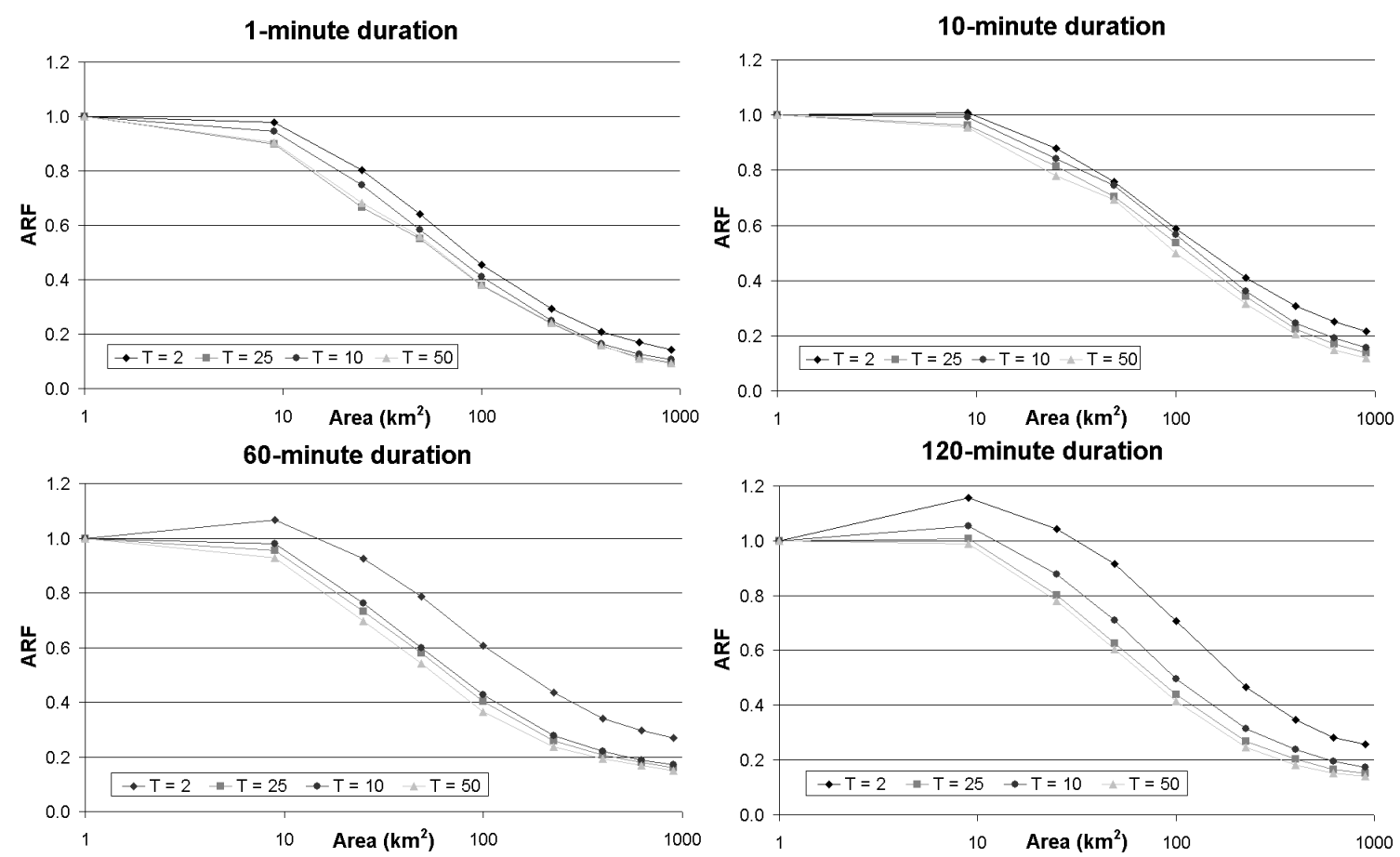

Fig. 6. Semi-logarithmic plots of the ARF trends with increasing area for each return period ( $T=2,10,25$ and 50 years) selected at different durations.
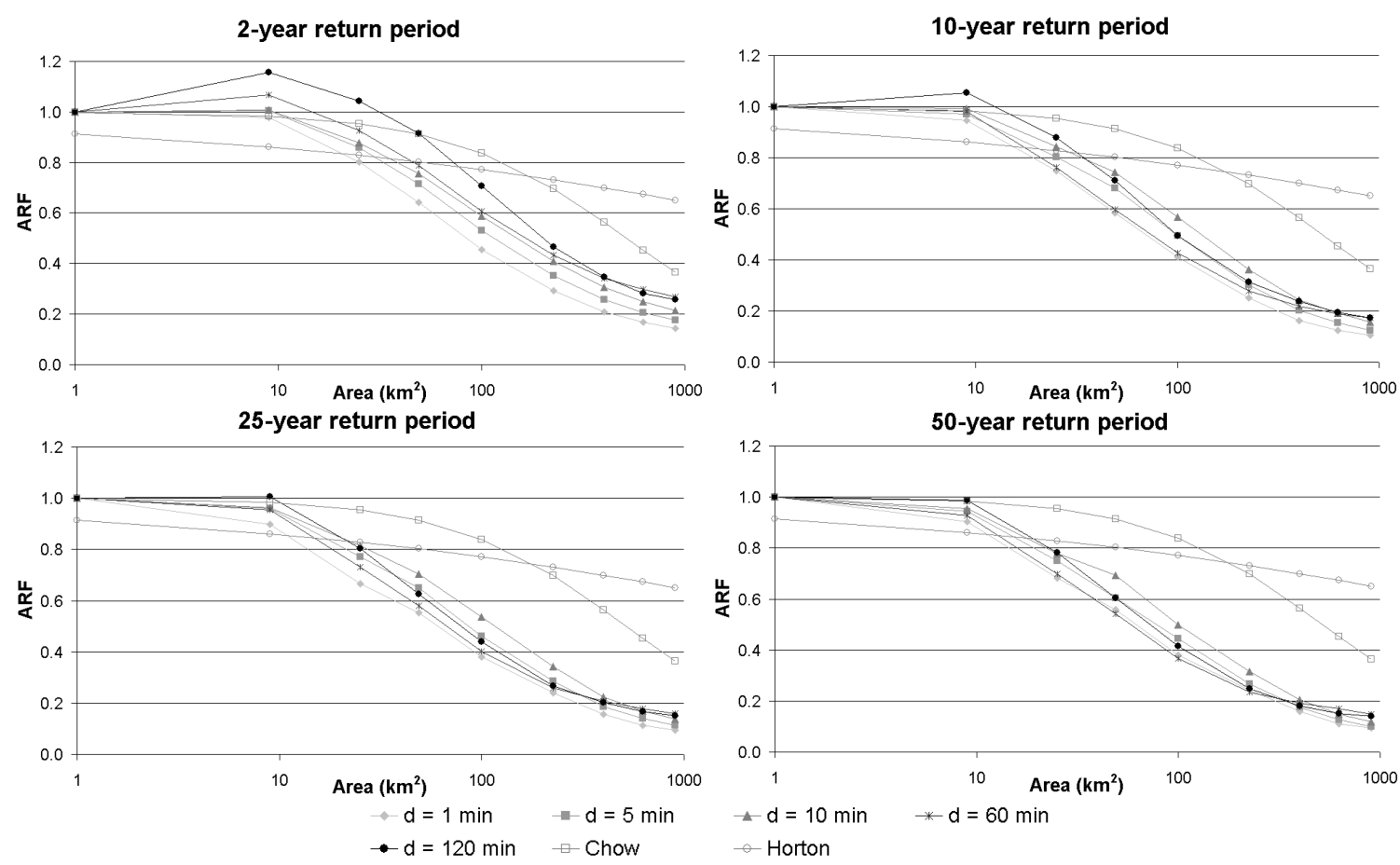

Fig. 7. Semi-logarithmic plots of the ARF trends with increasing area for various durations and return periods shown against some ARF-area literature relationships which only depend upon the area. 

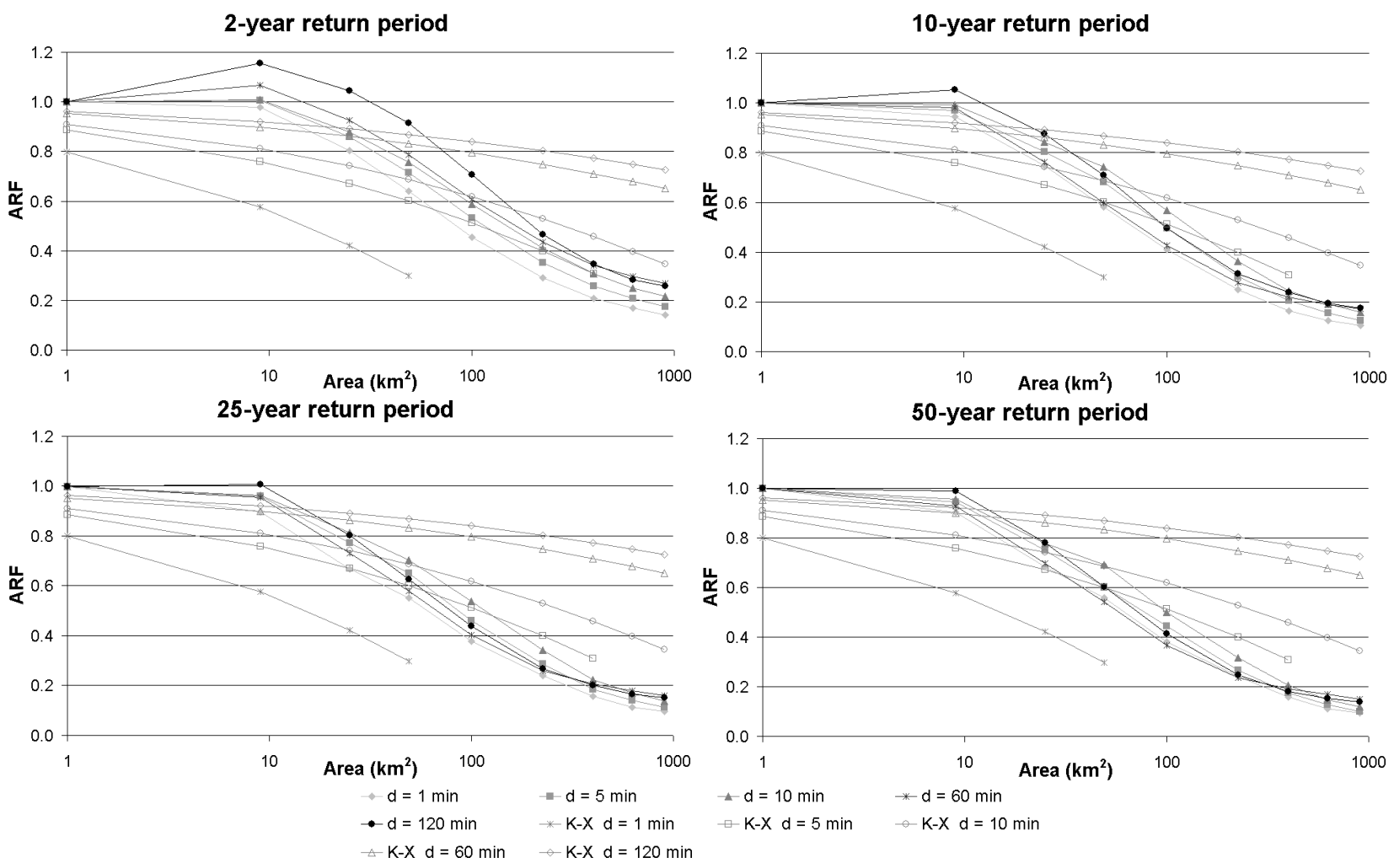

Fig. 8. Semi-logarithmic plots of the ARF trends with increasing area for various durations and return periods shown against ARF-area Koutsoyiannis and Xanthopoulos relationship which is a function of the area and the duration.

method shown in Table 2. Thus, the values in Table 2 are assumed as threshold intensities allowing us to calculate the ARF depending on the return period.

As a matter of fact, the only pixels on which the ARF is calculated are those with an intensity higher than the said threshold intensity for each time aggregation and return period considered.

In order to analyse the ARF trend when increasing the area, the size of the above-mentioned pixels were increased with an upscaling process until we had rainfall estimates over an area of $900 \mathrm{~km}^{2}$ (see Fig. 3). The rainfall intensity over each "increased" pixel is calculated as described above.

\section{Comparison with existing methods}

The data set used in our work contains several radar recordings, thus the ARF values are estimated in an asynchronous setting of equal return periods.

Box plots of the results for each return period selected, the 1-min (see Fig. 4), and 120-min duration (see Fig. 5) are shown. In either case, the bigger the area, the less spread out the data sample. The sample spreadness also reduces when the return period increases.
Besides, the trends of the 95th percentile of the ARF data sample when increasing the area for each return period selected at different durations are shown in Fig. 6. The higher the duration, the higher the ARF. Note that the ARF is greater than one for small areas and high durations.

Finally, we show ARF-area trend (the 95th percentile of the ARF data sample) against some of the most important empirical ARF-area relationships found in the literature (see Figs. 7 and 8):

- Chow (1964) relation:

$$
\mathrm{ARF}=\left(1+\frac{1.93 A}{10^{3}}\right)^{-1}
$$

- Horton's relation (Natale, 2003):

$$
\mathrm{ARF}=\exp \left(-0.09 \cdot A^{0.23}\right)
$$

- Analytical relationship developed to approximate the NERC (1975) ARF values, which is also in good agreement with Weather Bureau (1960) figures (Koutsoyiannis and Xanthopoulos, 1999):

$$
\mathrm{ARF}=1-\frac{0.048 A^{0.36-0.01 \ln A}}{d^{0.35}}
$$


Table 2. Rain intensity values $(\mathrm{mm} / \mathrm{h})$ over the whole radar scanning region calculated for each duration $(\delta=1,5,10,60$ and $120 \mathrm{~min})$, and return period ( $T=2,10,25$ and 50 years) selected by using the arithmetic-mean method and the Thiessen method.

\begin{tabular}{lccccc}
\hline \multicolumn{6}{c}{ Arithmetic-mean method (A) } \\
$T$ (years) & $\mathrm{i}_{\delta=1}$ & $\mathrm{i}_{\delta=5}$ & $\mathrm{i}_{\delta=10}$ & $\mathrm{i}_{\delta=60}$ & $\mathrm{i}_{\delta=120}$ \\
\hline 2 & 133.0 & 103.3 & 82.1 & 31.0 & 19.2 \\
10 & 206.4 & 160.4 & 127.6 & 48.1 & 29.9 \\
25 & 243.3 & 189.1 & 150.4 & 56.7 & 35.2 \\
50 & 270.7 & 210.5 & 167.4 & 63.1 & 39.2 \\
\hline \multicolumn{5}{c}{ Thiessen method (T) } \\
$\mathrm{T}$ (years) & $\mathrm{i}_{\delta=1}$ & $\mathrm{i}_{\delta=5}$ & $\mathrm{i}_{\delta=10}$ & $\mathrm{i}_{\delta=60}$ & $\mathrm{i}_{\delta=120}$ \\
\hline 2 & 133.4 & 103.6 & 82.4 & 31.1 & 19.3 \\
10 & 207.6 & 161.4 & 128.4 & 48.3 & 30.0 \\
25 & 245.0 & 190.5 & 151.5 & 57.1 & 35.4 \\
50 & 272.7 & 212.0 & 168.7 & 63.6 & 39.5 \\
\hline
\end{tabular}

Percentage difference between A to $\mathrm{T}$

\begin{tabular}{lccccc}
$\mathrm{T}$ (years) & $\mathrm{i}_{\delta=1}$ & $\mathrm{i}_{\delta=5}$ & $\mathrm{i}_{\delta=10}$ & $\mathrm{i}_{\delta=60}$ & $\mathrm{i}_{\delta=120}$ \\
\hline 2 & 0.3 & 0.3 & 0.4 & 0.2 & 0.5 \\
10 & 0.6 & 0.6 & 0.6 & 0.5 & 0.5 \\
25 & 0.7 & 0.7 & 0.7 & 0.7 & 0.7 \\
50 & 0.7 & 0.7 & 0.8 & 0.7 & 0.6
\end{tabular}

where $A$ the area in $\mathrm{km}^{2}$ and $d$ the duration in $\mathrm{h}$ (the relationship is valid when the resulting ARF is not less than 0.25 ).

It is evident that all of the empirical curves overestimate the ARF for large areas $(A)$ and high durations, especially for higher return periods. Also, it is possible to note that empirical curves underestimate the ARF for small areas and return periods.

\section{Conclusions}

The results obtained in the processing of the data set using this technique have been compared with some of the most important published empirical equations for the areal reduction factor.

The results seem to be important in floodplain management as well as in the design of urban drainage systems. For small and medium size basins (200-900 $\mathrm{km}^{2}$ ), 25-50 year return periods, and $1-2 \mathrm{~h}$ concentration times, we estimate ARF values ranging from 0.1 to 0.3 while empirical curves in literature estimate ARF values ranging from 0.4 to 0.8 , thus causing a remarkable overestimation of rainfall.

Furthermore, on the basis of the assumptions done, the results seem to lead also to consequences in hydrologic design for urban drainage systems, in which small areas and return periods are usually considered. In these cases our work shows that no ARF smaller than one should be applied to point rainfall measurements, in order to avoid underestimating rainfall and consequently the storm sewers.

The methodology should be applied to different areas and climatologies in order to generalize the results.

Acknowledgements. The authors thank E. Gorgucci of the Institute of Atmospheric Sciences and Climate of the National Research Council for interesting discussions and for providing the radar data. This research was partially supported by the National Group for Defense from Hydrogeological Hazards of the National Research Council (GNDCI-CNR, Italy).

Edited by: M. Bruen

Reviewed by: D. Koutsoyiannis

\section{References}

Asquith, W. H. and Famiglietti, J. S.: Precipitation areal-reduction factor estimation using an annual-maxima centered approach, J. Hydrol., 230, 55-69, 2000.

Austin, P. and Houze, R.: Analysis of the structure of precipitation patterns in New England, J. Appl. Meteorol., 11, 926-935, 1972.

Bacchi, B. and Ranzi, R.: On the derivation of the areal reduction factor of storms, Atmos. Res., 42, 123-135, 1996.

Calenda, G., Cioffi, F., Guercio, R., and Petaccia, A.: Rainfall assessment with inadequate data, Urban Storm Drainage, Water Resources Publications, Hyland Ranch, USA, 23-44, 1993.

Chow, V. T.: Handbook of Applied Hydrology, New York, McGraw-Hill, 1964.

Chow, V. T., Maidment, D. R., and Mays, L. W.: Applied Hydrology, New York, McGraw-Hill, 1988.

De Michele, C., Kottegoda, N. T., and Rosso, R.: The derivation of areal reduction factor of storm rainfall from its scaling properties, Water Resour. Res., 37(12), 3247-3252, 2001.

Gorgucci, E., Scarchilli, G., and Chandrasekar, V.: Radar and surface measurements of rainfall during CaPE, J. Appl. Meteorol., 34, 1570-1577, 1995.

Gringorten, I. I.: A plotting rule for extreme probability paper, J. Geophys. Res., 68(3), 813-814, 1963.

Koutsoyiannis, D.: Statistics of extremes and estimation of extreme rainfall, 1, Theoretical investigation, Hydrol. Sci. J., 49(4), 575590, 2004a.

Koutsoyiannis, D.: Statistics of extremes and estimation of extreme rainfall, 2, Empirical investigation of long rainfall records, Hydrol. Sci. J., 49(4), 591-610, 2004b.

Koutsoyiannis, D., Kozonis, D., and Manetas, A.: A mathematical framework for studying rainfall intensity-duration-frequency relationships, J. Hydrol., 206(1-2), 118-135, 1998.

Koutsoyiannis, D. and Xanthopoulos, T.: Engineering Hydrology, Edition 3, 418 pages, National Technical University of Athens, Athens, 1999.

Natale, L.: Idrologia tecnica, in: Manuale di ingegneria civile e ambientale, edited by: Rossi, F. and Salvi, F., Zanichelli - Esac, Bologna, 2003.

National Environmental Research Council (NERC): Flood studies report, Institute of Hydrology, Wallingford, 1975.

National Weather Service (NWS): Rainfall intensity-frequency regime, Technical Paper 29, Silver Spring, Md., 1958. 
Roche, M.: Hydrologie de Surface, Gauthier-Villars, Paris, 1966.

Rodriguez-Iturbe, I. and Mejia, J. M.: On the transformation of point rainfall to areal rainfall, Water Resour. Res., 10(4), 729$735,1974$.

Russo, F., Napolitano, F., and Gorgucci, E.: Rainfall monitoring systems over an urban area: the city of Rome, Hydrol. Processes, 19(5), 1007-1019, 2005.

Sivapalan, M. and Blösch, G.: Transformation of point rainfall to areal rainfall: Intensity-duration-frequency curves, J. Hydrol., 204(1-4), 150-167, 1998.
U.S. Weather Bureau: Generalized estimates of probable maximum precipitation west of the $10^{\text {th }}$ meridian, Technical Paper 38, U.S. Department of Commerce, Washington, DC, 1960.

Veneziano, D. and Langousis, A.: The areal reduction factor: A multifractal analysis, Water Resour. Res., 41(7), W07008, doi:10.1029/2004WR003765.

World Meteorological Organization (WMO): Manual for estimation of probable maximum precipitation, Operational Hydrology Report, 1, WMO Paper 332, Geneva, Switzerland, 1986. 